\title{
Effects Of Crude Oil On Aquatic Insects Of Tundra Ponds
}

\author{
SAMUEL C. MOZLEY ${ }^{1}$ and MALCOLM G. BUTLER ${ }^{2}$
}

\begin{abstract}
Aquatic insects are numerous and important in the ecology of tundra thaw ponds, comprising most of the biomass and production. The most common types are the caddisflies Asynarchus and Micrasema, the stonefly Nemoura, the beetle Agabus and especially larvae of the fly family Chironomidae. Studies in vitro showed no detectable mortality of these insects at doses of oil up to $1.51 / \mathrm{m}^{2}$ Prudhoe Bay crude oil. However, field experiments on two ponds with application rates of about $101 / \mathrm{m}^{2}$ (Pond E, 1970) and $0.241 / \mathrm{m}^{2}$ (Pond $\Omega, 1975$ ) both indicated that selective elimination of Asynarchus and Nemoura had occurred. Chironomidae in Pond $\Omega$ displayed much lower rates of adult emergence in 1976 and 1977 than in 1975, immediately before and after oil treatment, with several species in the tribe Tanytarsini most reduced. Pond E did not show low emergence rates, but the proportion of Orthocladiinae was much higher than in reference ponds. Trichotanypus was severely reduced in Pond $\Omega$ but unusually abundant in Pond E in 1976 and 1977. Effects of oil seem to be different for different species, and occur at some point during the late larval stages of insects or at metamorphosis, but toxicity experiments did not confirm this. Oil may also interfere with reproduction in insect species which remain mainly on or near the pond surface as adults. Apparent effects in field experiments are not entirely consistent with observations of Canadian researchers. Nevertheless there were several similarities and both followed patterns like those observed in marine benthic communities, such as greater effects on shore fauna, greater effects of low-molecular-weight hydrocarbons, and species-specificity of effects. There is no indication of recovery of Nemoura, Asynarchus or Tanytarsini in Pond $\mathbf{E}$ seven years after the spill, but biomass and abundance of the other aquatic insects remains high. We recommend that clean-up measures avoid introducing solvents or dispersants, which might be toxic to insects in the ponds.
\end{abstract}

RESUME. Les insectes aquatiques sont nombreux et importants dans l'écologie des étangs de toundras, dégelés; ils forment la majeure partie du biotope - les genres les plus communs sont les phryganes Asynarchus et Micrasema, le lithoptère Nemoura, les coleoptères Agabus et surtout les larves de la famille volante de Chironomides. Les études "in vitro" n'ont pas révélé de mortalité visible de ces insectes pour une eau polluée de "brut" de Prudhoe Bay jusqu'à $1.51 / \mathrm{m}^{2}$. Cependant, les expériences sur place, sur deux étangs, avec des teneurs de $101 / \mathrm{m}^{2}$ (Etang $\mathrm{E}$ en 1970 ) et $0.241 / \mathrm{m}^{2}$ (Etang $\Omega$ en 1975) ont toutes les deux prouvé une disparition élective des Asynarchus et Nemoura. Dans l'étang $\Omega$, on constatait une arrivée à l'âge adulte des Chironomides, très inférieure en 1976 et 1977 qu'en 1975, immédiatement avant et après traitement au pétrole. Quelques espèces de la famille de Tanytarsins étaient les plus affectées. On ne constatait pas les mêmes diminutions sur l'étang $\mathbf{E}$; par contre la proportion des Orthocladins était beaucoup plus forte que dans les étangs témoins - le genre Trichotanypus était sévèrement réduit sur l'étang $\Omega$ mais curieusement restait abondant sur l'étang $E$ en 1976 et 1977 . Les effets du pétrole paraissent se situer vers la fin du stade larvaire des insectes ou lors de leur metamorphose mais les expériences de toxicité n'ont pas confirmé cette hypothèse. Le pétrole peut agir aussi au temps de la reproduction des espèces d'insectes qui adultes, restent surtout sur la surface de l'étang ou à proximité. Les observations ne paraissent pas en complet accord avec les observations des chercheurs Canadiens. Il n'y a pas d'indication de redressement des

'Department of Zoology, North Carolina State University, Raleigh, North Carolina, U.S.A.

${ }^{2}$ Division of Biological Sciences, University of Michigan, Ann Arbor, Michigan, U.S.A. 
Nemouras, Asynarchus ou Tanytarsus sur l'étang E, sept ans après la pollution mais le biotope et l'abondance d'autres espèces aquatiques restent importante.

Nous recommandons que les mesures de nettoyage évitent d'utiliser des solvents ou des dispersants dans les étangs - celà pourrait être toxique aux insectes.

Traduit par Alain de Vendigies, Aquitaine Co. of Canada Ltd.

\section{INTRODUCTION}

Thaw ponds in the low coastal tundra near Barrow, Alaska cover a large proportion of the land surface (Miller and Hobbie, this volume). The ponds, as distinguished from larger, deeper lakes, freeze completely for more than nine months each year, and are rarely more than $40 \mathrm{~cm}$ deep. Most ponds have two distinct benthic habitats, peripheral stands of Carex aquatilis Wahlenb, and Arctophila fulva (Trin.) Rupr. which are submerged at the time of thaw up to 15 or $20 \mathrm{~cm}$ deep, and a deeper, central area of semi-fluid, almost completely organic sediments free of macrophytes. Water level in the ponds drops steadily during the summer, in dry years fully exposing the Carex stands. Habitat differences are reflected in species composition of the benthic fauna.

These ponds support substantial numbers (up to $40,000 / \mathrm{m}^{2}$ ) and biomass (up to $5.4 \mathrm{~g} \mathrm{dry} \mathrm{wt} / \mathrm{m}^{2}$ ) of aquatic insects, particularly larvae of the midge family Chironomidae, but only a few other kinds of macroinvertebrates are present (Mozley and Butler, in press). Insects in stands of Carex include stonefly nymphs (Nemoura arctica Ebsen-Petersen), caddisfly larvae (Asynarchus sp., Micrasema scissum McL.) and larvae and adults of beetles (Agabus sp.), in addition to chironomid larvae (primarily Corynoneura spp., Trichotanypus alaskensis Brund., Paratanytarsus penicillatus Goetgh. and Tanytarsus gregarius-group sp.). Other fauna includes the snail Physa and Turbellaria. In contrast, insects in semi-fluid sediments of the pond centers are almost entirely chironomids (largely Chironomus pilicornis (Fabr.), Tanytarsus inaequalis Goetgh.,Tanytarsus gregarius-group sp. and Procladius sp.) (Mozley, in press; Mozley and Butler, in press; Miller et al. 1977). Oligochaetes (Tubificidae and Enchytraeidae) are the only common non-insects. Aquatic insects are an important food of numerous birds which breed on wet tundra in summer (Holmes and Pitelka, 1968), and exert some control over the ecology of ponds by mixing sediments (Mozley and Butler, in press). In contrast to their numerical and ecological importance, the benthic species of thaw ponds have lower taxonomic diversity than temperate ponds.

The short thaw period and cool temperatures impose severe restraints on the developmental rates of chironomid larvae in Barrow ponds. Analysis of Chironomus pilicornis indicates that seven years are required to complete the life cycle, whereas the Tanytarsini take at least two and probably three years to mature. Thus, larval populations in the ponds represent between two and seven year-classes (Mozley and Butler, in press).

Our study focused on a simple, null hypothesis: that surface-applied crude oil would not cause changes in natural populations of the more abundant benthic species. Laboratory tests and observations were conducted at dose 
rates comparable to field experiments to aid in interpretation of field results. Studies of oil effects were supplemented with broader investigations of taxonomy, life history, and benthic secondary production with the goal of identifying mechanisms which elicited any responses to oil observed in natural populations.

The present paper mainly concerns new information which we have gathered since an earlier presentation (Mozley, in press). This consists of quantitative and qualitative collections of insects and other macroinvertebrates from Carex stands in 1977, further quantitative collections of adult chironomids emerging from selected ponds and additional in vitro experiments with oil toxicity. Our aim was to clarify the longer-term effects on insects in Pond $\Omega$ (treated in 1975) and to quantify apparent differences of insect composition in Carex stands between oil-treated and untreated ponds that were suggested by preliminary samples.

\section{METHODS}

Methods employed in studies of pond insects through 1977 have been described earlier (Mozley, in press; Mozley and Butler, in press). Two ponds, designated $\mathbf{J}$ and $\mathrm{G}$ were used as reference ponds, which were not treated, whereas two others were treated with Prudhoe Bay crude oil, Pond $\mathrm{E}$ in summer of 1970 at a rate of $101 / \mathrm{m}^{2}$ and Pond $\Omega$ in summer of 1975 at a rate of $240 \mathrm{ml} / \mathrm{m}^{2}$ (Fig. 1). Although some overflow occurs each June during thaw, the eastward trend of drainage did not carry oil into the reference ponds from Pond E. Pond $\Omega$ also did not drain toward the other reference ponds (Fig. 1).

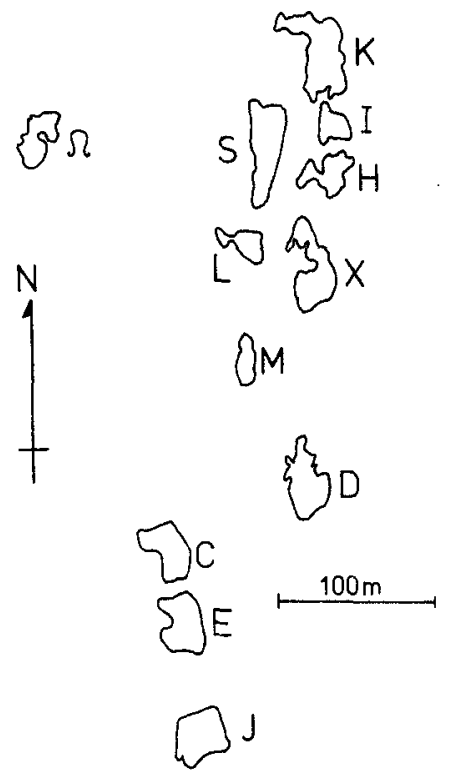

FIG. 1. Arrangement and relative sizes of Barrow thaw ponds subjectd to quantitative or qualitative studies of aquatic insects. 
The date on which Pond $\Omega$ was treated, July 8 , fell after most chironomid adults in the genera Trichotanypus and Tanytarsus had emerged and reproduced. Some of these were not sampled in 1975 because emergence traps were not installed until about one week after emergence began. Further information on the spills and the fate of the oil is given by Bergstein and Vestal, Miller, et al., and Miller and Hobbie, all in this volume.

Benthic populations in central, soft sediments were sampled with hand cores 35 or $17 \mathrm{~cm}^{2}$ in area and $10 \mathrm{~cm}$ long several times during thaw periods of 1975-1977. Animals were extracted by sieving and sucrose flotation, which was about $95 \%$ efficient in tests. Adults were trapped in $0.05 \mathrm{~m}^{2}$, clear plastic funnel traps resting on or floating just above the bottom, and traps were cleared every two or three days. Two or more traps were set in each habitat and pond. Biomass estimates were determined after drying overnight at $60^{\circ} \mathrm{C}$. Traps were set in Ponds E, $\Omega$ and $J$ in 1975 through 1977, and also in G in 1976 and 1977, but complete data on emergence in the reference ponds in 1977 were not available at this writing.

Insects living among Carex plants were collected quantitatively in ponds $\mathbf{J}$, $\Omega$ and E, and qualitatively in these and several other ponds in 1977 (Fig. 1). Quantitative collections were conducted with $0.05-\mathrm{m}^{2}$ cylinders inserted into the bottom among the plants at depths $\sim 10 \mathrm{~cm}$. Included stems were cut at the sediment and rinsed inside the sampler to remove animals, then discarded. Water within the sampler was then swept $10 \mathrm{x}$ with a $14.3-\mathrm{cm}$ diameter, $0.5-\mathrm{mm}$ mesh dipnet to suspend and remove larger insects. Insects and other animals were separated from sweepings with sugar flotation. Qualitative sweeps were made with a smaller net by collecting floating and barely submerged animals and materials from the downwind outer edge of Carex stands four times in each pond between June 22 and July 4, 1977.

Unreplicated tests for toxicity of surface-applied oil (i.e., not actively shaken or otherwise mixed into the water) were conducted in 201 glass aquaria in an incubator at $9{ }^{\circ} \mathrm{C}$ under continuous illumination from flourescent lights. A control aquarium was untreated and two or three others were treated at rates of $0.24,0.8$ or $1.51 / \mathrm{m}^{2}$ total water surface. Oil was confined to 25 or $50 \%$ of the available surface by a baffle which extended $2 \mathrm{~cm}$ below the water, and the oil-free end was slowly aerated with bubbles from a standard hypodermic syringe. Some observations were made with animals free to come into contact with oil, but in most tests the animals were confined in nylon screen cages. Animals were considered to be dead when they failed to move in response to a stream of water directed on them from a pipette. No observations of recovery were made. Tests with Asynarchus, Nemoura, Agabus larvae and adults and Physa and Turbellaria were conducted in 1975, with several Chironomidae and Micrasema, and again with Nemoura and Asynarchus in 1976. In addition, several tests of chironomid egg hatching and pupal metamorphosis were conducted in $250 \mathrm{ml}$ beakers at a dose rate of about 1 $1 / \mathrm{m}^{2}$. 
RESULTS

\section{Emergence of Chironomid Adults}

Emergence of adults from Pond $\Omega$ was as low in 1977 as in 1976, and both years were much lower than 1975, the year of oil treatment (Fig. 2). This was true both in Carex stands where the oil slick persisted and in the center of the pond where thin films occurred only occasionally when oil residues among plants were disturbed. Composition of the emerging adults by subfamily or tribe was quite similar in pond centers in 1976 and 1977, both years differing from 1975 in having a lower percentage of Tanytarsini. In peripheral stands of Carex, again the composition was similar in 1976 and 1977, and quite different from 1975, with a larger proportion of Orthocladiinae (especially Corynoneura spp.) and much smaller proportions of Podonominae (exclusively Trichotanypus alaskensis) and Tanytarsini.

Adults emerging from Pond $\mathrm{E}$ in 1977 were less numerous than in 1976, but proportions of subfamilies were similar between the years (Fig. 2). Orthocladiinae (especially Corynoneura and Metriocnemus) and Podonominae formed a greater proportion but Tanytarsini a lower proportion than in other ponds nearby (cf. Mozely, in press).

Reference ponds $J$ and $G$ also varied in number of adults emerging, both between themselves and from year to year (Mozley, in press; Mozley and Butler, in press). However, both yielded more adults than Pond $\Omega$ did in 1976 and 1977 , and proportional numerical composition by subfamily or tribe was
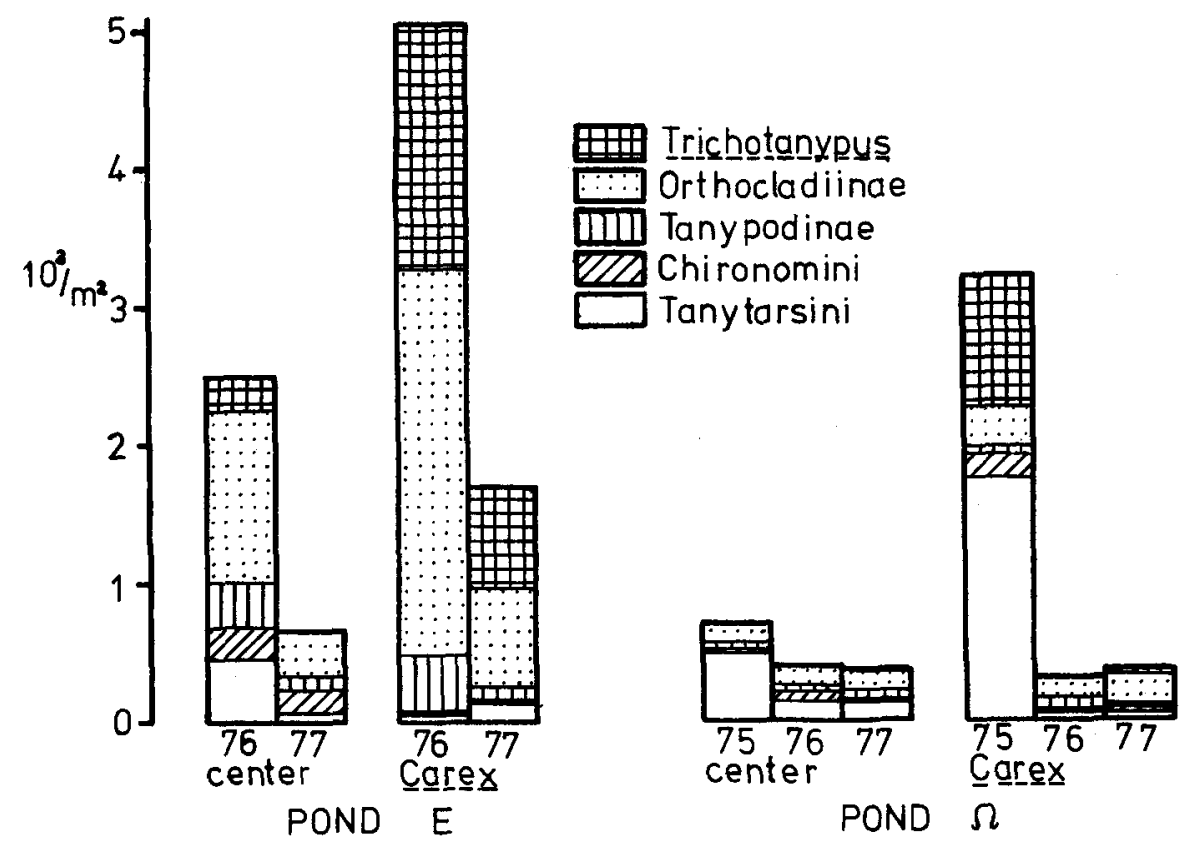

FIG. 2. Number of emerging chironomid adults per square meter by subfamily or tribe in the two ponds treated with oil. Trapping was continuous through the emergence season. 
much like Pond $\Omega$ in 1975 (partly prespill). Pond $E$ and $\Omega$ both had lower proportions of Tanytarsini and higher proportions of Orthocladiinae emerging from all habitats than reference ponds, but Pond E yielded large numbers of Trichotanypus whereas this species decreased in Pond $\Omega$.

Biomass of emerging adults was estimated from weights of males and females of common species, and numbers emerging in 1976. Pond E had the largest emerging biomass because of the high proportion of large-bodied Chironomini and Tanypodinae, whereas Pond J was second, Pond G third and Pond $\Omega$ yielded the least.

\section{Benthic samples}

Cores from pond centers gave a different picture from emergence traps. Composition by subfamily or tribe was similar in the cores and in emergence traps in 1975, but the sharp decrease in emergence in Pond $\Omega$ in 1976 and 1977 was not matched by larval mortalities of Chironomidae (Miller, et al., 1977). A total of $7,020 / \mathrm{m}^{2}$ larvae in 1976 compared well with $8,120 / \mathrm{m}^{2}$ in 1975 before the spill, and numbers were still high in 1977 (sample processing incomplete). It appeared that larval development had been arrested before metamorphosis, but we have not yet examined age distributions or growth patterns to test this possibility.

Other insects among Carex stands showed larval population changes, possibly responses to oil treatment. The caddisfly Asynarchus and the stonefly Nemoura arctica were undetected by quantitative sampling in Ponds $\mathrm{E}$ and $\Omega$ but composed most of the numbers (and because of their relative size,

TABLE 1. Quantitative samples of macroinvertebrates (excluding Chironomidae) from Carex stands in June and July 1977. (mean number per square meter \pm standard error, $\mathrm{n}=6$ )

Genus

Pond

\begin{tabular}{lll}
\hline J(reference) & E(oiled 1970) & (oiled 1975)
\end{tabular}

Agabus

(larvae)

$10.0 \pm 6.8 \quad 10.0 \pm 4.4$

0

Asynarchus

(larvae and pupae)

$40.0 \pm 11.6$

0

0

Micrasema

(larvae and pupae)

$26.6 \pm 8.4$

0

$13.3 \pm 6.7$

Nemoura

(nymphs)

$613 \pm 268$

0

0

Lebertia

$43.3 \pm 13.1$

$6.7 \pm 6.7$

$163 \pm 122$

Physa

$13.3 \pm 9.9$

$3.3 \pm 3.3$

0 
TABLE 2. Occurrence (x) of aquatic stages of insects in twelve ponds (see Fig. 1) as determined by qualitative net sweeps on four dates in early summer ${ }^{1}$ adults only. ${ }^{2}$ see Table 1.

\begin{tabular}{|c|c|c|c|c|c|c|c|c|c|c|c|c|}
\hline \multirow[t]{2}{*}{ Gènus } & \multicolumn{10}{|c|}{ Untreated Ponds } & \multicolumn{2}{|c|}{ Oil Ponds } \\
\hline & $\mathrm{C}$ & $\mathrm{D}$ & $\mathrm{H}$ & $\mathrm{I}$ & $\mathbf{J}$ & $\mathrm{K}$ & $\mathbf{L}$ & $\mathbf{M}$ & $\mathrm{S}$ & $\mathrm{X}$ & $\mathrm{E}$ & $\Omega$ \\
\hline Agabus & $\mathrm{x}$ & $\mathbf{x}$ & $\mathrm{x}$ & $\mathrm{x}$ & $\mathrm{x}$ & $\mathbf{x}$ & $\mathbf{x}$ & $\mathrm{x}$ & $\mathbf{x}$ & & $\mathrm{x}$ & 1) \\
\hline Asynarchus & $\mathrm{x}$ & $\mathrm{x}$ & $\mathrm{x}$ & $\mathrm{x}$ & $x$ & $\mathrm{x}$ & $\mathrm{x}$ & $\mathrm{x}$ & & $\mathrm{x}$ & & \\
\hline Micrasema & & & $\mathrm{x}$ & & 2) & & $\mathrm{x}$ & & $\mathbf{x}$ & & & 2) \\
\hline Nemoura & $\mathrm{x}$ & $\mathrm{x}$ & $\mathbf{x}$ & & $\mathbf{x}$ & & & & $\mathbf{x}$ & $\mathbf{x}$ & & \\
\hline Physa & & $\mathrm{x}$ & & & 2) & & & $\mathrm{x}$ & & & 2) & \\
\hline
\end{tabular}

biomass) of larger invertebrates in Pond $\mathrm{J}$ (Table 1). Agabus (beetle)-larvae were common in $\mathrm{J}$ and $\mathrm{E}$, but undetected in $\Omega$. Micrasema, a brachycentrid caddisfly, was common in $\Omega$ and $\mathrm{J}$, but absent from $\mathrm{E}$. Besides the insects, the only mollusk in Barrow ponds, Physa sp., was missing from samples in Pond $\Omega$ but present in E and J. Mites (mainly Lebertia sp.) were present in all three ponds and most numerous in Pond $\Omega$.

\section{Qualitative Samples in Carex Stands of 12 Ponds}

Qualitative samples from a larger number of ponds essentially followed the patterns of differences which were evident between treated and untreated ponds in the quantitative study. Nemoura, for example, was found in $60 \%$ of ten untreated ponds but neither $\mathrm{E}$ nor $\Omega$ (Table 1). Untreated ponds in which it was not found were relatively small and shallow. Asynarchus or its cast larval skin was found in $90 \%$ of untreated ponds, but neither of the treated ones. Agabus larvae or larval skins were collected in $90 \%$ of untreated ponds and in Pond E, but not in $\Omega$. Micrasema, however, was present in $40 \%$ of untreated ponds and Pond $\Omega$, but not in Pond E. There was no apparent characteristic in common among ponds with or without Micrasema. The snail Physa was present in only $30 \%$ of untreated ponds, whereas mites seemed to be poorly sampled in qualitative collections. These patterns suggest that Asynarchus and Nemoura are eliminated by oil treatment and return very slowly if at all (one Nemoura has been observed in Pond E but none were taken in samples).

\section{Laboratory Tests}

Surface-applied oil in aquaria caused no immediate death, nor any detectable difference in mortality between treatments and controls, over periods of 12-21 days at the dose rates employed. The highest rate was more than six times that applied to Pond $\Omega$, yet no mortality occurred in those species which seemed to be eliminated from the pond, i.e., Nemoura and Asynarchus. There was steady mortality in the experiments, but it appeared to 
be due to handling or to interruption of normal developmental stimuli in the environment. In contrast, Agabus larvae and adults were soon trapped in the floating oil when not separated from it by screening. They did not die immediately but were unable to free themselves and would have starved eventually. The same would likely be true of the other insects if given access to the oil along Carex stems and leaves to which oil was adhering. However, transferral of these observations to the ponds is complicated by the lack of information on behaviour in situ. Agabus, for example, was present in the treated ponds, possibly by post-spill immigration of the adults from adjacent ponds.

Observations at intervals when mortality was tallied indicated that insect larvae under oil had lower levels of activity than those in control aquaria, but time constraints of maintaining the emergence sampling and other field work precluded quantification of this.

Similarly, no difference could be observed in rates of egg hatching for species of Chironomus, Procladius and Tanytarsini in beaker experiments. There was some mortality but also complete hatching in both oiled and control beakers. Emergence of at least one species of pupa would occur through thin $(\sim 0.5 \mathrm{~mm})$ oil slicks, but pupae were trapped by thicker slicks. There was no indication of abnormal, pre-emergence pupal mortality in several trials of this type.

\section{Further Observations}

The unusual behavior of mating on the pond surface appeared to increase the susceptibility of some species to oil. Tanytarsus gregarius-group sp. actually swarmed on the water surface near stands of Carex, and adults of several other Tanytarsini and Orthocladiinae seemed to remain among emergent plants rather than flying away from the ponds as did the larger Chironomus and Tanypodinae. An undetermined quantity of the slick was strained for entrapped adults on Pond $\Omega$ in 1975 , and many Chironomidae were among these. However, we could not ascertain whether these were a significant fraction of the total because of numerous heterogeneities in the system, such as slick distribution, distribution of adults and differences among the Carex stands.

Since the senior author's previous report (Mozley, in press), two differences attributed to oil treatment between Pond $\mathrm{E}$ and reference ponds have been reconsidered in view of other data. A large number of Psectrocladius spp. (Orthocladiinae) larvae in the center of Pond $E$ in 1975 and high rates of Psectrocladius emergence from Pond E in 1976 now appear to be possibly unrelated to the oil. Pond D nearby has proved to have a similarly high proportion of Psectrocladius. Moreover, emergence of Psectrocladius was much lower in 1977 and the high population levels in 1976 may prove to have been transitory. The second difference was in the high proportion of oligochaetes in Pond E benthic samples. Review of older data (Bierle, 1973) shows that proportions of oligochaetes can vary within this range among untreated ponds. 


\section{DISCUSSION}

\section{Interpretation of Field Experiments}

Field experiments offer several benefits beyond the usual laboratory tests of toxicity in evaluating the effects of oil on benthos. When natural ponds are treated, we have a chance to test predictions based on oil toxicity in a situation much like that of accidental spills, and to observe the system-wide effects. System-wide effects may be more extensive than toxicity would lead us to expect, for secondary responses of aquatic insects to zooplankton mortality (O'Brien, this volume), periphyton growth (Snow and Rosenberg, 1975) or other effects such as changes in sediment cohesiveness when the oil sinks, suppression of wind-mixing by the slick, and interference with mating and oviposition may be quite important. On the other hand, animals in their natural habitat with normal food and substrate, undisturbed and adjusted to their microhabitat may be much less sensitive than the same animals in vitro.

However, field experiments present several problems in documenting and interpreting any apparent effects. Differences between oil-treated and untreated ponds may arise from natural, between-pond or year-to-year variations in population sizes of the insects. Moreover, subtle environmental differences and biological interactions within and between ponds may introduce high variance into replicate samples or give rise to a priori differences between populations in different ponds. Distinction between such differences and the effects of oil would take years of study of production and life history because of the natural year-to-year variations. It is therefore desirable to interpret results of field experiments conservatively and document apparent effects by more controlled experiments whenever feasible.

In most experimental studies, results of laboratory tests are never confirmed in the field, but our results are of a different sort. Although no toxicity was detected in vitro, there were several apparent effects of oil in treated ponds, and we can only speculate on the mechanisms which might have produced them. Although the apparent effects are subject to the problems just mentioned, we feel it is better to consider the connection with oil to be probable until disproven so that potential ecological damage of oil spills is not overlooked.

\section{Apparent Effects of Oil on Insects}

The most severe changes were noted at the species, rather than the community level. Pond E, subjected to the heavier spill, had densities and emerging biomass of chironomids equal to or greater than reference ponds by 1976. While the apparent loss of larger insects from the Carex stands might have some repercussions in the midge assemblage, such as improved survival of epiphytic larvae of Trichotanypus and Corynoneura, it is hard to imagine that much change has occurred in overall energy flow or carbon transport. Had we only observed Pond $\Omega$, we might have come to a quite different conclusion. Suppression of emergence rates there could have serious consequences for insectivorous birds if a spill were widespread, but the condition of Pond $\mathrm{E}$ six years after the spill indicates that recovery of emergence rates is complete. 
Even reduction in the normally dense populations of Tanytarsini would seem to be of negligible importance in comparison to the (perhaps improved) survival and emergence of large-bodied species.

The principal feature in common among petroleum hydrocarbon effects in various bodies of fresh water has been the differential susceptibility of various species. Tubb and Dorris (1965) describe the success of three chironomid species in refinery effluent holding ponds in Oklahoma, noting that Tanypus stellata Coq. was most resistant to toxic effects. McCauley (1966) saw a change in benthic composition, primarily elimination of the predators Agrion (Odonata) and Dugesia (Turbellaria) and the omnivore Gammarus (Amphipoda) from stretches of a stream with oily sediments, whereas deposit-feeding Tubifex (Oligochaeta), Chironomus, Nematoda and predaceous Hirudinea persisted. Rosenberg and Wiens (1976) divided species responses in experimental oil spills into categories of negative, positive and indifferent, and showed that different species of Chironomidae occurred in each category. Similarly, spills in Mackenzie Delta lakes affected certain chironomids more than other chironomids and oligochaetes (Snow and Rosenberg, 1975). However, freshwater benthic studies of oil effects are too few and habitats too diverse to make more detailed generalizations.

There are some similarities but also some differences in apparent effects of oil between our study and those of Snow and Rosenberg (1975) and Rosenberg and Wiens (1976). Similarities are that effects seemed to be more severe in shallower habitats, and that Tanytarsini were affected negatively while Orthocladiinae increased following oil treatment. Both we and they observed entrapment of many insects in the oil slick along downwind edges of ponds or lakes. However, our sampling later indicated that some insects which were entrapped by the slicks persisted in treated ponds (Micrasema, Agabus), others did not (Nemoura, Asynarchus). Snow and Rosenberg (1975) observed increases in oligochaetes in oil-treated ponds as we did in Pond E, but because of between-pond variation we are unable to make a positive statement that this was a response to the treatment (Mozley, in press). Snow and Rosenberg (1975) reported severe mortality of chironomid larval stages, but our laboratory experiments at comparable oil doses and field experiments in Barrow ponds showed no detectable mortality of larvae. Effects on Orthocladiinae in Barrow primarily concerned increases in Corynoneura populations, although 1976 data also suggested a positive response of Psectrocladius (see above). Orthocladiinae increases in Canadian experiments were mainly due to Psectrocladius and Rosenberg and Wiens (1976) say that Corynoneura was negatively affected in stream experiments.

\section{Benthic Response Patterns}

The U.S. National Academy of Science (1975) has provided a summary of marine work which suggests principal patterns in benthic community responses. First, the type of oil and the amounts of it which reach the benthic habitat are probably the most important factors. Low-molecular-weight petroleum hydrocarbons and confined embayments are the worst conditions, 
whereas oils high in non-volatile hydrocarbons and open coasts are the least severe. Oil has its greatest effect on intertidal benthos when the slick washes ashore, i.e., comes into massive, direct contact with the animals. Subtidal benthos are frequently unaffected, but when they are the oil has come into contact with them by coating inorganic sediment particles or being driven below the surface by dispersants or turbulence. The importance of dissolved fractions to benthic animals is probably minor in contrast to their high toxicity for planktonic copepods. Benthic effects were noted in at least some instances when dispersant chemicals were applied to put surface slicks into suspension. However, it appeared that the dispersants themselves were more toxic than the oil.

Laboratory experiments have mostly involved oil which has been driven into aequeous suspension by stirring or shaking. Oil-water mixtures can have profound effects, from simple mortality to cancerous lesions of reproductive organs and subtle alterations in behavior, even at low concentrations. The consequences of most such effects are reduced rates of growth, reproduction or both, necessarily followed by population declines (Dow and Hurst, 1975; Barry and Yevich, 1975; Olla and Samet, 1975).

There appears to be a difference in susceptibility of various subtidal species to oil spills. In several cases these differences appear to follow a pattern of elimination of crustacean filter feeders (e.g. Ampelisca), then early recovery of colonization of affected areas by the opportunistic, deposit-feeding polychaete, Capitella. Perhaps sediments provide some protection against oil, whereas suspended particles near the sediments are relatively high in oil droplets or oil-coated particles. Differences also occur among species which are similar in feeding habits and belong to the same taxon (Stirling, 1977).

Some similarities are immediately obvious between marine and Barrow pond spills. The effects were species-specific and quite possibly a consequence of direct contact with the floating slick by larvae or adults. Moreover, in the less turbulent pond environment, there was little effect on subsurface benthos but greater changes among insects the Carex stands, a habitat analogous in some ways to the marine intertidal because of fluctuating water levels. Apparently lower toxicity to benthos of Prudhoe Bay crude oil than Norman Wells crude oil, which has a larger volatile fraction (Snow and Rosenberg, 1975), also follows the marine pattern. Our data and the Canadians' are suggestive of a stronger effect on filter feeders (Tanytarsini) than burrowing deposit feeders (oligochaetes) but results are not conclusive. One of the greatest similarities is that benthos of deeper habitats are much less susceptible than plankton.

The more detailed aspects of behavioral and reproductive changes may also occur in Barrow ponds, but our data do not apply to these questions. Unlike marine benthos aquatic insects must undergo extensive developmental changes and pass through the water surface to reproduce, and the effects of oil on these processes may be unique to insects. It would be advisable in future experimental studies to examine responses of metamorphosis, feeding and growth of larvae to oil more closely. 
These comparisons have been necessarily at a superficial level. Whether they can be accurately extrapolated to larger arctic waters or to ponds at lower latitudes is not clear because of considerable differences in species composition between these others and Barrow ponds (Mozley and Butler, in press). Preliminary, unpublished observations in an arctic lake by the senior author suggest more severe benthic effects than were observed in Barrow ponds. Moreover, our dose rates were small in comparison to sites near accidental spills and terrestrial studies reported elsewhere in this volume. Effects of more massive spills on ponds might be more extensive.

The long life cycles of arctic aquatic insects would slow the rate of recovery from large spills, but this would be important only if oil damage to benthic populations was severe. However, observations in Pond E do not indicate that lighter spills on thaw ponds will have serious effects on benthos. The emerging cohort of Chironomus in 1977, for example, presumably hatched in the year of the spill and has completed its development with a density as large as in the reference Pond $\mathrm{J}$.

\section{Recovery}

Data which would show recovery of aquatic insects after the 1970 treatment of Pond $\mathrm{E}$ with oil are meager. In the first place, many chironomids, and especially large Chironomus which make up most of pond secondary production (Mozley and Butler, in press), were not affected by oil so there was apparently no effect on energy flow (see also Bierle, 1973). Tanytarsini are relatively low in density seven years after treatment. If entrapment of adults were an important cause of their low density, one would expect that transferral of floating oil to sediments would have permitted recolonization by 1977. Nemoura and Asynarchus have not established populations there. The only indication of recovery is the presence of large populations of Trichotanypus in contrast to its decrease in Pond $\Omega$. Again, we can only infer from Pond $\Omega$ that Trichotanypus was initially killed by oil in Pond E; there are no supportive data from Pond $\mathrm{E}$ in 1970-74.

\section{Remedial Action After Oil Spills}

In view of the relatively mild effects evident in Pond $\mathrm{E}$, and the nature of changes in aquatic insect populations in both $E$ and $\Omega$, it would be advisable to avoid drastic measures to remove oil which might in themselves have a greater effect than the oil. At most, use of inert materials to absorb oil slicks, or possibly flooding of ponds to float oil away from Carex stands (cf. Snow and Rosenberg, 1975) might be considered. Given the importance of pond insects as food for migrating birds in summer, it is especially crucial that clean-up efforts avoid use of volatile solvents or other potentially toxic chemicals unless still more important ecological considerations warrant it.

\section{ACKNOWLEDGEMENTS}

This work was supported by subcontracts to the University of Michigan from US ERDA Contract E-(40-1)-4943 with North Carolina State University and US ERDA E(11-1)-2989 with the Marine Biological Laboratory. Appreciation is expressed to John Hobbie who was principal investigator on the prime contracts. Many thanks to Jay W. Chaplin, who identified Micrasema and Dave White, who identified Nemoura, and Asynarchus. 


\section{REFERENCES}

BARRY, M., and P. P. YEVICH. 1975. The ecological, chemical and histopathological evaluation of an oil spill site. Part III. Histopathological Studies. Marine Pollution Bulletin, 6:171-3.

BERGSTEIN, P. E., and J. R. VESTAL. 1978. Crude oil biodegradation in arctic tundra ponds. Arctic (this volume).

BIERLE, D. A. 1973. Macrobenthic populations in ponds of the arctic coastal tundra. U.S. International Biological Program, U.S. Tundra Biome, Data Report no. 73-26, 20 p. 8 Figs. 1-12 and Tables I-VIII.

DOW, R. L., and J. W. HURST. JR. 1975. The ecological, chemical and histopathological evaluation of an oil spill site. Part I. Ecological Studies. Marine Pollution Bulletin. 6:164-6.

HOLMES, R. T. and F. A. PITELKA. 1968. Food overlap among coexisting sandpipers on northern Alaskan tundra. Systematic Zoology. 17:305-18.

McCAULEY, R. N. 1966. The biological effects of oil pollution in a river. Limnology and Oceanography. 11:475-86.

MILLER, M. C., V. ALEXANDER, and R. BARSDATE. 1978. Effects of oil on phytoplankton populations in lakes and ponds. Arctic (this volume).

MILLER, M. C., and J. E. HOBBIE. 1978. Ecology of tundra thaw ponds and the oil spills of 1970 and 1975. Arctic (this volume).

MILLER, M. C., J, R. VESTAL, S. MOZLEY, M. BUTLER and J. E. HOBBIE. 1977. Effects of Prudhoe crude oil spills on coastal tundra ponds. U.S. Environmental Protection Agency, Decision Series, Energy/Environment II, Publ. no. EPA-600/9-77-012, pp. 521-529.

MOZLEY, S. C., (in press). Effects of experimental oil spills on Chironomidae in Alaskan tundra ponds. Verhandlungen Internationale Vereinigung Für Theoretishce und Angewandte Limnologie., 20.

MOZLEY, S. C. and M. G. BUTLER. (in press). Macrobenthos. In: HOBBIE, J. E., (ed.), Ecology of Arctic Thaw Ponds. New York, Methuen Press.

O'BRIEN, J. 1978. Effects of crude oil on zooplankton in arctic ponds. Arctic (this volume).

OLLA, B. L., and C. SAMET. 1975. Behavior of marine organisms as a measure of petroleum contamination. Proceedings of the Estuarine Research Federation, Outer Continental Shelf Conference Workshop, Dec. 2-4, 1974, "Marine Environmental Implications of Offshore Oil and Gas Development in the Baltimore Canyon Region of the Mid-Atlantic' Coast," Univ. Maryland. pp. 437-50.

ROSENBERG, D. M. and A. P. WIENS. 1976. Community and species responses to Chironomidae (Diptera) to contamination of fresh waters by crude oil and petroleum products, with special reference to the Trail River, Northwest Territories. Journal of the Fisheries Research Board of Canada., 33:1955-63.

SNOW, N. B., and D. ROSENBERG. 1975. Experimental oil spills on Mackenzie delta Lakes. I. Effect of Norman Wells crude oil on Lake 4. Canada Fisheries Marine Service, Tech. Report no. 548, 44 p.

STIRLING, H. P. 1977. Effects of a spill of marine diesel oil on the rocky shore fauna of Lamma Island, Hong Kong. Environmental Pollution. 12:93-117.

TUBB, R. A., and T. C. DORRIS. 1965. Herbivorous insect populations in oil refinery effluent holding pond series. Limnology and Oceanography. 10:124-34.

U.S. NATIONAL ACADEMY OF SCIENCES. 1975. Petroleum in the Marine Environment. Washington, Publishing and Printing Office of the National Academy of Sciences, $107 \mathrm{p}$. 